\title{
Conflict Behaviours of
}

\section{Administrators in Long Term Care}

\section{Facilities Influence Facility Ratings:}

\section{SOS-Semantics of Self in Conflict ${ }^{T M}$}

\section{Barbara Sunderland Manousso}

\begin{abstract}
Long term care (LTC) facilities, also called nursing homes, are often ripe for conflicts which cause stress for residents, their families and staff. This article presents the results of a survey showing how nursing facility administrators in Harris County, Texas, managed conflict within their facilities and how a more positive approach was consistently reflected in how their facilities were rated in US government quality consumer ratings. The concept at the centre of this study, SOS-Semantics of Self in Conflict ${ }^{T M}$, recognises that the degradation of standards due to conflict is not just an event in a nursing care facility. It is a process that is heavily influenced, and in some cases exacerbated, by the way in which facility administrators react to conflict. These reactions have important broader implications for the facility's best practice retrospectively.
\end{abstract}

\section{Introduction}

As more people live longer, a higher percentage of the population find they cannot live independently. Illnesses associated with advanced age mean that an increasing number need daily medical care (Monk, Kaye, \& Litwin, 1984; Shield \& Aronson, 2003). Many become dependent on long-term residential care in nursing facilities, also known as nursing homes.

While some residents adapt to the new routines and environments, others encounter conflict and miscommunication. This can make living in long-term care nursing facilities (LTCs) challenging and potentially threatening to their health. Stress and a lack of communication occasionally end in medical errors and fatalities. 
LTCs are ripe for many types of conflicts among various combinations of staff, administrators, residents, residents' family members and caregivers. The kind of personal, intimate, continuous interactions which take place in LTCs all provide opportunities for conflicts. This is a challenge for management and senior administrators need a variety of inter-personal skills and strategies to prevent and resolve conflict as quickly as possible. It is essential that they can do this so as to establish and maintain harmony and good quality patient care (Persson, 2003; Minick \& Gueldner, 1995; Wood, 2004).

Festering conflicts and disruptive behaviours are a killer for staff and patients alike, and are likely to increase the incidence of high, costly, staff turnover (Vogele \& Steptoe, 1992; Vogele \& Steptoe, 1993).

Unfortunately, LTC residents usually do not have many, if any, options to remove themselves from conflict. Also, the emotions of family members are often intense and can be fueled by feelings of guilt for having left their loved ones in the impersonal setting of an LTC, thereby adding to staff conflicts.

In the LTC industry, staff turnover is common because pay is usually low for both direct patient care attendants and professional staff. Stress is often increased because some facilities are understaffed and carers overworked (Chesney, 1996).

There has been relatively little systematic study on the dynamics and impact of conflicts in LTCs. However, there is a modest amount of information on the conflict management style of LTC administrators in the literature and this indicates that conflict can distupt the chain of communication. One study looked at self-reported conflict behaviours of 140 nursing home administrators to see if a correlation existed between the way they behaved when faced with conflict and the state and federal ratings of their facilities.

The survey instrument used to measure and rate the administrators' self-reported conflict behaviours was the Conflict Dynamic Profile (CDP) (Runde \& Flanagan, 2007). It measures four activeconstructive, three passive-constructive, five active-destructive, and four passive-destructive attributes. Each has a numerical ranking corresponding to the respondent's self-perceptions of how they manage conflict.

Table 1 lists the four categories of behaviours associated with conflict management and outlines their defining attributes. The leadership attributes which were found to be especially useful in resolving conflicts have an asterisk attached in the table. They are positively related to the leadership style known as strategic leadership. These were looked at specifically in relation to facility ratings (retrieved from http://www.conflictdynamics.org/cdp/about/dynamic_conflict.php). 
Table 1 CDP Conflict Management Behaviours

\begin{tabular}{|l|l|}
\hline \begin{tabular}{l|l|}
\hline Active-constructive & Active-destructive \\
Cerspective taking* & Winning at all costs \\
Expressing emotions & Displaying anger \\
Reaching out & Demeaning others \\
& Avoidance \\
Retaliating
\end{tabular} \\
\hline $\begin{array}{l}\text { Passive-constructive } \\
\text { Delay responding* }\end{array}$ & $\begin{array}{l}\text { Passive-destructive } \\
\text { Reflective thinking* }\end{array}$ \\
Adapting* & $\begin{array}{l}\text { Hiding emotions } \\
\text { Dominance }\end{array}$ \\
\hline
\end{tabular}

The Questionnaire that the participants completed was administered and scored online and was generated to each participant's email address with a numerical code.

The second component of this study was Medicare's five star quality rating. Medicare provides national health care for Americans over 65 years old. In 2008, Medicare rolled out a national rating system for LTCs so that consumers could have a better understanding of each facility's quality of care. It considers facilities under three categories, each with an overall rating designed to adjust and accommodate more comparable ratings nationally and to help consumers compare LTC facilities within a geographic area. This rating system numerically rates three key categories: health inspections, nursing home staffing and quality measures. The ratings range from one star (much below average) to five star (much above average). These ratings are summarised and each facility is ranked from one to five with an overall mean rating.

Table 2 Five Star Quality Rating

\begin{tabular}{|c|c|}
\hline Much above average & 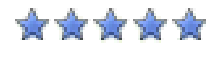 \\
\hline Above average & 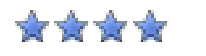 \\
\hline Average & 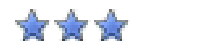 \\
\hline Below average & 类类 \\
\hline Much below average & 춧 \\
\hline
\end{tabular}

Retrieved from

http://www.medicare.gov/NHCompare/Include/DataSection/Questions/HomeSelect.asp a.pss 
Information on each facility, some self-reported by the facilities, is gathered monthly by federal and state agencies who work in tandem. Sometimes these agencies investigate facilities because of complaints reported by residents and their families or because the state and federal agencies found deficiencies on their scheduled visits.

The five star quality rating survey has been adjusted to accommodate for urban and rural facilities since the study participants were from LTCs in urban areas. The Overall facility reviews of May 2011 were the Quality Ratings used in this study.

One Star out of five for an overall score represents a facility with very serious staff issues, quality of care, and facility problems. Three Stars represent an average facility. Five Stars indicate a top quality facility that offers the most comfort and care for residents. Two and four ratings are bridges to either better or worse ratings.

This study investigates the impact of the administrator's self-reported behaviours in conflict management, as ranked and provided on their Conflict Dynamic Profile CDP-I survey, and their facility rating. The study sought to establish if the administrators' active-constructive leadership skills were a predictor of above-average facility ratings.

\section{The problem}

As is often reflected in workplaces, as well as in ongoing relationships, conflicts develop on many levels. People dealing directly and indirectly with conflict often believe that they are dealing with the problems it creates in a productive way. However, objective criteria, like that retrieved from a reliable survey, can reveal the opposite.

In LTCs there are additional conflict dynamics involving staff and non-staff, such as residents and their families (Antonucci, Fuhrer and\& Dartigues, 1997). These conflicts often do not have the pattern participants or observers expect, so communication can be quite destructive to the relationships which are essential to enabling a facility to deliver high quality care. Personal communication is stifled and often derailed by tension and misunderstandings (Pillemer, Suitor \& Henderson, 2003).

The literature on conflict management recognises this. Katz (2006) observed: "[] eaders demonstrate their responsiveness by communicating warmth and concern, listening to and respecting the aspirations of others, and giving people the resources, autonomy, and opportunity to succeed and do their job." When communication is shut down, conflict is more likely to develop. 
It is particularly important to address issues of conflict in nursing home settings, since the residents usually do not have many, if any, options to remove themselves from the conflict (Ames, 1995). The turnover of staff is often high, because of low pay, especially for the direct patient care attendants who often lack education and options for mobility. In addition, physicians and nurses can challenge each other's professional ideas (Weitzman, \& Weitzman, 2006). The presence of all these factors increases the potential for conflict.

Social conflict theory offers a framework that can provide insight into conflict dynamics in LTC facilities. Homans, a social process theorist and an observer of social conflict in exchange theory (especially in equity theory), suggests that "conflict is especially tense when persons see themselves committed to a social relationship that is inequitable, for often one cannot easily leave such relationships" (in Schellenberg, 1996, p74). The staff and administrators have power over the residents. If conflict arises, the residents are often too frail, unmotivated, or limited to certain facilities by financial constraints to be able to leave.

Staff with limited career alternatives, or who feel they need to work close to home, often feel unable to challenge their administrator or leave a conflict setting. This leads to an inequitable system in which authority comes from the top down, passing in diminishing degrees to staff, patients and their families.

While no studies appear to exist that independently examine the conflict behaviours of LTC administrators, anecdotal observations suggest that conflicts in nursing homes may often be a result of administrators' behaviours. It has been suggested that the quality of conflict resolution skills of administrators can affect the quality of care in nursing homes (Monk et al, 1984).

\section{Research question}

Is there a relationship between nursing facility administrators' self-reported conflict behaviour attributes and scores on the individual conflict dynamic profile (CDP-I) and their facility's five star quality rating?

\section{Hypotheses}

$\mathbf{H}_{1} \quad$ Administrators with higher conflict dynamic profile mean scores from the seven values of active and passive constructive conflict behaviours will lead facilities that have overall quality ratings of four or five stars.

$\mathbf{H}_{2} \quad$ Administrators with the highest mean scores from the eight values of active and passive destructive conflict behaviours will have quality ratings of one or two stars. 
$\mathbf{H}_{3}$ This study expects to find a positive Pearson $\mathrm{r}$ correlation, $+/-1$, between administrators' selfreported active and passive constructive conflict behavioural skills on the five recognised leadership attributes (perspective taking, creating solutions, delay responding, reflective thinking, adapting) with higher facility quality ratings of four or five stars.

$\mathbf{H}_{0} \quad$ The null hypothesis was that there is no measurable correlation or significant association between the administrators' higher or lower mean scores on the individual conflict dynamic profile (CDPI) with their facilities' higher or lower five star quality rating.

\section{Methodology}

This was a quantitative study, correlating information from long term care and nursing home administrators who completed a reliable, valid, tested instrument - the CDP-I - with public information from the Medicare database, the five star quality rating that compares national nursing homes. There were no known studies to base this study on, so the methodology was original.

\section{Sample}

The purposive sample, $n=140$, consisted of all the executive directors or administrators of the 140 nursing homes with five star quality ratings located in Harris County, Texas, and neighbouring counties, as reported in the public Medicare report of March 2011. The participants who consented to volunteer self-selected to participate in this study after receiving a request for their participation from the University of Texas Harris County Long-Term Care Ombudsman programme.

Harris County, Texas, is the fourth largest county in the United States. The administrators, staff and residents of the LTCs studied were from a variety of ethnic, economic and religious groups in an urban area. Harris County and its surrounding areas had more than six million registered residents as reported in the 2011 Harris County demographics by Dr Stephen Klineberg of the Kinder Institute at Rice University's School of Sociology. (Retrieved at http://www.datahouston.org/khas/KHASALL\%20Codebook\%20(1982-2018).pdf.)

\section{The Conflict Dynamic Profile}

The individual conflict dynamic profile (CDP-I) was developed by Craig Runde and Tim Flanagan at Eckerd College's Leadership Development Institute in St Petersberg, Florida. It is a tool to analyse conflict behaviours and leadership attributes (Runde \& Flanagan, 2007). The advantage of using this survey instrument was that it measured behaviour attributes and not styles or personality traits. Behaviours can be learned, but personality is more organic and difficult to change. (Retrieved at http://www.conflictdynamics.org/cdp/about/dynamic_conflict.php.) 


\section{Medicare's five star quality rating database}

The second component of this study, Medicare's five star quality rating, was rolled out in 2008 to rate nursing homes, so that consumers could find the best performing nursing homes in one area. There are three categories rated with an overall rating. Each facility's ratings were based on each state's investigations, following federal protocol.

The five star quality rating survey was adjusted to accommodate for urban and rural facilities, regional differences, ratios of staff to residents, the number of beds, and services offered. It was also tested for validity and reliability (Personal communication of Jan Tarantino, Deputy Director of the Five Star Quality Rating Website in Fort Worth, Texas, in July, 2009). (Retrieved at http://www.medicare.gov/NHCompare/Include/DataSection/Questions/SearchCriteriaNEW.asp?versi on $=$ default\&browser $=I E \% 7 C 8 \% 7 C W$ indows + Vista\&language $=$ English. $)$

\section{Data-collection methods and analysis}

In this study, each administrator was assigned a random, coded numerical unique identifier to conceal their identity. The overall rating of each of the facilities' three scores from health inspections, nursing home staff, and quality measures was compared with the summary of the facility administrators' CPD-I mean scores of their seven constructive behaviours and their eight destructive behaviours. To accomplish this analysis, the researcher examined the value of Pearson's correlation coefficient that varied between +1 and -1 . The CDP-I scores of the administrators were correlated and plotted with the overall ratings of the facilities.

\section{The results: $\mathrm{H} 1$ affirmed}

The results of this study affirmed that administrators with the higher conflict dynamic profile individual mean scores derived from the seven values of active and passive constructive conflict behaviours led facilities with overall quality ratings of four or five stars.

The immediate and practical results were that this study also provided the 140 participating long term care and nursing home administrators with an objective insight into their conflict behavioural styles. It also gave them reliable data and an explanation on how they applied constructive and destructive, active and passive, behavioural skills. The participators' results on their behaviours contributed to their understanding of how future constructive and destructive conflict management skills can affect the overall quality ratings of their nursing facility. This made them more aware of how they dealt with conflict and of the implications of this for their facility. 


\section{SOS-Semantics of Self in Conflict ${ }^{T M}$}

The researcher of this study developed and trademarked a theoretical framework to frame both the administrators' perceived behavioural attributes in conflict events and the trickle-down effects these might have on their facility. The theory was that SOS-Semantics of Self in Conflict ${ }^{\mathrm{TM}}$ offers a framework to allow administrators in nursing homes and health care facilities to be mindful of their conflict behaviours and adapt them to improve outcomes.

Semantics is defined as to how one perceives signs and symbols, so the concept is to look at how administrators view conflict after reviewing the conflict event, understanding their behaviours and then, by applying the learned information, reconstructing the cause and effect and reflecting on their role and various alternatives. This sequence of the event can be expressed by structure, process, and outcome. Therefore, the study result was that the administrator sets the conflict tone for their facility by their constructive and destructive behaviours that flow to the other staff through a trickledown effect.

\section{Theory and discussion of SOS-Semantics of Self in Conflict ${ }^{\mathrm{TM}}$}

The following theory of SOS-Semantics in Conflict emerged from this study.

In the general health care industry, structure, process, and outcome have been used to measure quality within a health care setting. For purposes of funding and productivity, these three elements are the core indicators of the effectiveness of health care delivery systems.

In the The Blackwell Handbook of Mediation, edited by Peggy Herrman in 2006 (Katz, 2006) structure, process, and outcome are also variables that can or should be measured in conflict resolution processes. Taking this concept to a more personal, direct micro level for administrators who deal with conflict in nursing homes and long-term care facilities, provided the framework for SOS-Semantics of Self in Conflict ${ }^{\mathrm{TM}}$, a theoretical framework which originated from this study.

The researcher's hypothesis was that the CDP-I behaviour attributes would be the same for nursing home administrators as it was for the corporate community, and that there would be a positive relationship between administrators with more effective conflict behaviours and the higher quality ratings of their facilities. The outcome of this study suggested that this was somewhat true, although the actions of the direct care staff varied with the nature of each conflict within the culture of each facility, prompting a new model or way of looking at behavioural attributes particular to the nursing home industry. 
The Semantics of Self (SOS) is the administrator's initial response to a conflicting event. Semantics of Self in Conflict refers to the people involved in the conflict action. It does not necessarily mean that an administrator was directly involved in the conflict - although they could be. The fact that they could be leaves open the possibility that conflicts are often corrected, analysed, or responded to by somebody who was directly or indirectly responsible for what happened.

In semantics, how one perceives signs and symbols provides the structure around which subsequent assumptions are built. In this introduced model, there is the nursing home administrator's perception of the conflict event (the structure) and how they use conflict behaviours that they have tested in previous conflict situations, chosen to use, or exchanged for a particular response. This is the process of the model. The behaviour around the conflict produces the outcome, which has ripple effect that reverberates on the conflict event.

What makes this conflict model different is that it is reviewed and responsive in reverse. It does not start with the reaction of the recipient to the conflict behaviour, as the CDP-I is designed; the model starts with the outcomes or reverberations of the conflict event. The reverberation is what is seen first and overlays the other parts of the model. The reverberation could be that a patient dies due to a miscommunication or the retaliation of an angry, underpaid and overworked nurses' aide. Reverberation could be the anger of a family member that his or her parent's call button was not answered and their parent fell trying to get out of bed to visit the bathroom. These are two common scenarios in LTC facilities that can lead to licence review, potential lawsuits, complaints about poor quality of care and a reflection of this in state and federal facility reviews and ratings.

Conflict behaviour is human behaviour, learned from an early age. The development of behaviour is a constant interplay between "the real world, the world of aesthetics, the world of ethics, and the model world. To make a speculation about human behavior, you begin by working backward" (Lave March, 1975, p. 78).

Figure 1 demonstrates the visual representation of SOS-Semantics of Self in Conflict ${ }^{\mathrm{TM}}$. The choice of behaviour, adaptation and exchange models all relate to each other and are the conflict behaviour responses. There could be many more responses but these are the ones that relate to this study.

Choice of behaviour aligns with the CDP-I's behavioural attributes. The CDP-I has recognised for many years the key conflict behaviours that are representative of best practice in leadership and management in organisations. These were the behaviours self-selected and assessed by the CDP-I.

Adaptation is one of the conflict behaviour attributes recognised by the Eckerd University Leadership Institute (Runde and Flanagan, 2007), as a productive passive-constructive skill, an asset to 
leadership ability. Talbot Parsons (Kivisto, 2001) saw adaptation as one of the four universal problems confronting every social unit. In functionalism, adaptation "refers to how a social system supports itself in relationship to an external environment" (Kivisto, 2001, p.159). This aligns with the concept of not having direct control over an event, but the need to respond to it. The flexibility of an organisation is built around the leader's ability to be nimble and to use the skill of adaptation as a problem-solving tool to deal with social and conflict situations.

Exchange theory is the interconnector among many theories and embraces rational choice theory. As mentioned above, exchange theory maximises one's gains of value. There is an exchange of behaviours, such as active, passive, constructive and destructive. A particular behaviour is selected because the result of using it is known or expected. With the SOS, there is a calculation of what the reverberation will be by using the conflict behaviour rationally selected. The SOS is the alert that a behaviour label needs to be selected to get a desired result. The process becomes more calculated than spontaneous.

Choice of behaviour, adaptation, and exchange stand alone or interweave to address the conflict behaviour response. The conflict event is what appears to be the conflict. This event can be seen differently by the observers. Perceptions are at the core of conflict. As in a mediation session, when each party tells the story of the conflict it often seems that they are not even talking about the same event. Differences in perception colour, frame, and provide the meaning and narrative of the conflict event. The language used, whether verbal or non-verbal, makes a difference in the value, impact and reality of the event. Therefore, the self in conflict is a combination of the conflict event, the perception of it, and the behavioural response to it. How one perceives the signs and symbols of it is the reverberation that makes up the SOS-Semantics of Self in Conflict ${ }^{\mathrm{TM}}$ (see Figure 1).

In summary, theoretically, in response to research, it is not the event that creates repercussions; it is the translation of the behavioural attributes used that initiate the repercussion or reverberation retroactively. 
Figure 1. Model of SOS-Semantics of Self in Conflict ${ }^{\mathrm{TM}}$

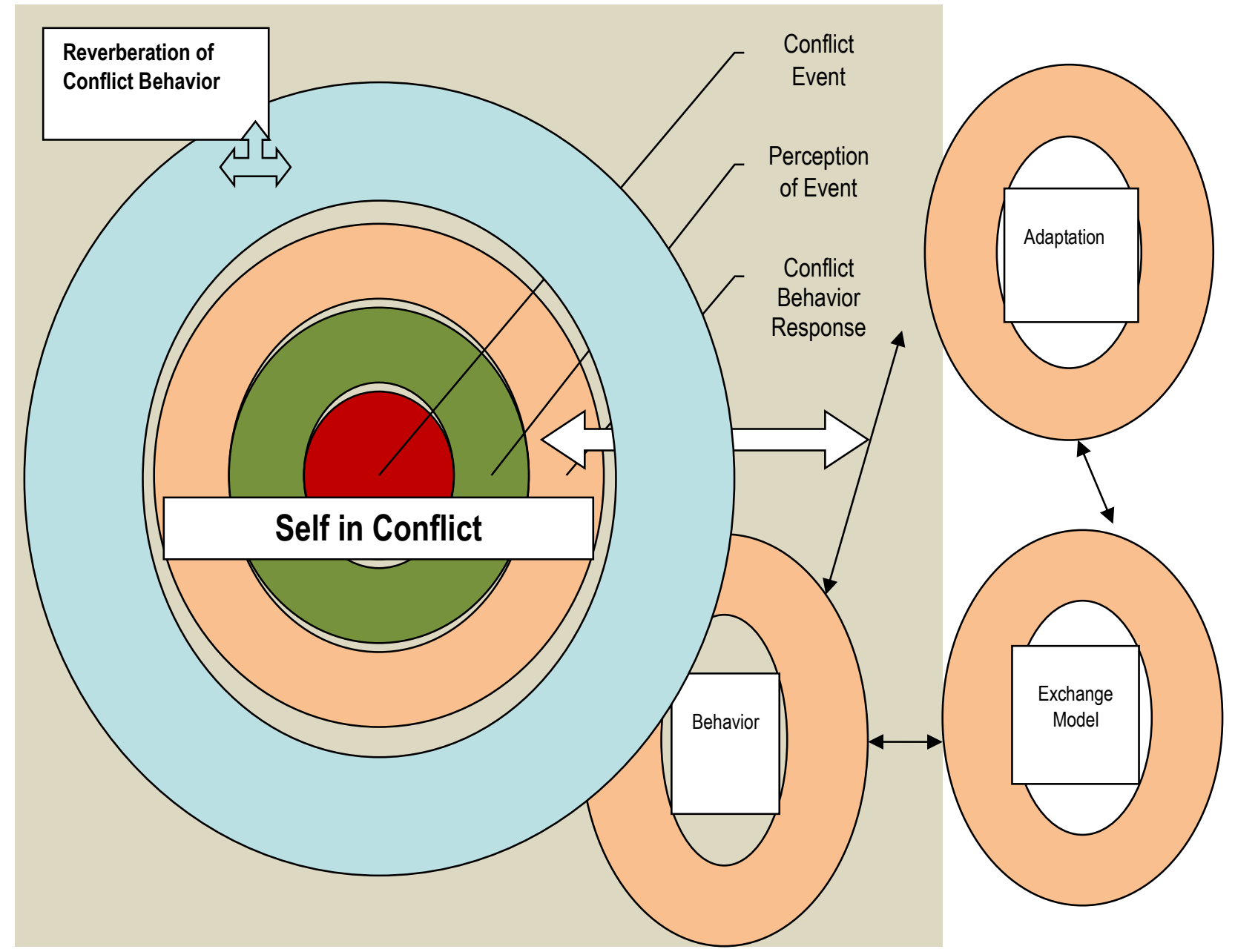




\section{Bibliography}

Ames, D. (1995). Epidemiological studies of depression among the elderly in residential and nursing homes. In E. Murphy \& G. Alexopolous (Eds.), Geriatric psychiatry: Key research topics for clinicians (pp. 152169). Chichester, UK: Wiley.

Antonucci, T. C., Fuhrer, R., \& Dartigues, J. (1997). Social relations and depressive symptomatology in a sample of community-dwelling French older adults. Psychology and Aging, 12, 189-195.

Babbie, E. (2004). The Practice of Social Research (10 th ed.) Belmont, CA: Thompson Wadsworth.

Birkhoff, J.E. (1997). Conflict Resolution Syllabi Anthology. Washington, DC: National Institute of Dispute Resolution.

Burger, S.G., Fraser, V., Hunt, S., \& Frank, B. (1993). Nursing homes: Getting good care there (2nd ed). Atascadero, CA: Impact Publishers, Inc.

Chesney, M.A. (1996). New bahavioural risk factors for coronary heart disease: Implications for intervention. In K. Orth-Gomer \& N. Schneiderman (Eds.), Bahavioural Medicine Approaches to Cardivascular Disease Prevention (pp. 169-182). Hillsdale, NJ: Erlbaum.

Cox, E.O. \& Parsons, R.J. (1992). Senior-to senior mediation service project. The Gerontologist, $\underline{32}$, (pp. 420-422).

Creswell, J. W. (1998). Qualitative Inquiry and Research Design: Choosing Among Five Traditions. Thousand Oaks, CA: Sage.

Creswell, J. W. (2003). Research design: Qualitative, quantitative, and mixed methods approaches. Thousand Oaks, CA: Sage.

Estes, C., Zulman, D. M., Goldberg, S., \& Ogawa, D.D. (2004). State long term care ombudsman programs: Factors associated with perceived effectiveness. The Gerontologist, 44, 1, (pp. 104-115).

Gladstone, J.W. (1995). Elderly married persons living in long term care institutions: A qualitative analysis of feelings. Ageing \& Society, 15, 493-513.

Health Resources and Services Administration (1997). Women's health in the medical school curriculum: Report of a survey and recommendations. Washington, DC: Author.

Hoover, K. \& Donovan, T. (2004). The Elements of Social Scientific Thinking (8th ed.). United States: Thomson Wadsworth

Karp, N. \& Wood, E. F. (1997). Keep Talking, Keep Listening: Mediating Nursing Home Care Conflicts: Commission on Legal Problems of the Elderly. Washington, D.C.: American Bar Association.

Katz, N. (2006). Enhancing Mediator Artistry: Multiple Frames, Spirit, and Reflection in Action. In M. S. Herrman (Ed.) The Blackwell Handbook of Mediation: Bridging Theory, Research, and Practice (pp.374-383). Malden, MA: Blackwell Publishing.

King, G., Keohane, R., \& Verba, S. (1994). Designing Social Inquiry: Scientific inference in Qualitative Research. Princeton University Press.

Kopper, B. A. \& Epperson, D. L. (1996). The experience and expression of anger: Relationships with gender role socialization, depression, and mental health functioning. Journal of Counseling Psychology, 43, (pp.158-167). 
Liu, K., McBride, T., \& Coughlin, T. (1994). Risk of entering nursing homes for long versus short stays. Medical Care, 32, (pp.315-327).

May, T. (2001). Social research: Issues, methods, and process. Philadelphia: Open University Press.

Minick, P., \& Gueldner, S. H. (1995). Patterns of conflict and anger in women sixty years and older: An interpretive study. Journal of Women and Aging. 7: (pp.71-84).

Moody. H. (1992). Ethics in an aging society. Baltimore: John Hopkins University Press.

Monk, A., Kaye, L., \& Litwin, H. (1984). Resolving Grievances in the nursing home: A study of the ombudsman program. New York: Columbia University Press.

Mor, V., Branco, K., Fleishman, J., Hawes, C., Phillips, C., Morris, J., \& Fries, B. (1995). The structure of social engagement among nursing home residents. Journal of Gerontology: Psychological Sciences, 50B, (pp.1-8).

Ostwald, S.K., Runge, A., \& Lees, E, et al. (2003). Texas Certified Volunteer Long- Term Care

Ombudsmen: Perspectives of Role and Effectiveness. Clinical Experience. JAMDANovember/December, (pp.323-328).

Pearson, L. (1988). Neighborhood dispute resolution: Seniors belping seniors. Washington, DC: American Association of Retired Persons.

Perkinson, M. A. \& Braun, K. (2000). Teaching students geriatric research. New York: Hawthorne Press.

Persson, D. (2003). The Roleplayer: Through the years, Ombudsmen are an ally for long term care. Contemporary Long Term Care. Houston, TX.

Pillemer, K., Suitor, J., Henderson, C., et al. (2003). A cooperative communication intervention for nursing home staff and family members of residents. The Gerontologist, 43, Special Issue II, 96-106.

Rubin, J. Z., Pruitt, D. G., \& Kim. (1994). Social Conflict. (2nd ed.). San Francisco: Jossey-Bass.

Runde, C.E. \& Flanagan, T.A. (2007). Becoming a Conflict Competent Leader: How You and Your Organization can Manage Conflict Effectively. San Francisco, CA: Jossey-Bass.

Russell, D.W., Cutrona, C.E., de la Mora, A., \& Wallace, R.B. (1997). Loneliness and nursing home admission among rural older adults. Psychology and Aging, 2, (pp. 574-589).

Schellenberg, J.A. (1996). Conflict Resolution: Theory Research, and Practice, Albany, NY: State University of New York.

Seidman, I. E. (1991). Interviewing as Qualitative Research: A Guide for Researchers in Education and the Social Sciences. NYC, NY: Teachers College Press.

Sheild, R. R. \& Aronson, S. (2003). Aging in Today's World: Conversations between an Anthropologist and a Physician. NY: Berghahn Books

Stafford, P. (2002). Gray Areas: Ethnographic Encounters with Nursing Home Culture. Santa Fe, NM: School of American Research Press.

Steptoe, A., Fieldman, G., Evans, O., \& Perry, L. (1996). Cardiovascular Risk and Responsivity to Mental Stress: The influence of age, gender and risk factors. Journal of Cardiovascular Risk, 3, (pp. 83-93).

Thomas, W. H. (2004). The search for being. AARP Bulletin, November, 30-31. 
Umbreit, M.S. (1995). Mediating Interpersonal Conflicts: A Pathway to Peace. West Concord, MN: CPI Publishing, (p. 165).

Vesperi, M. (1998). City of green benches: Growing old in a new downtown. Ithaca: Cornell University Press.

Vinton, L., \& Mazza, N. (1998). Intervening in family-staff conflicts in nursing homes. Clinical Gerontologist, 19, (pp. 45-68).

Vogele, C., \& Steptoe, A. (1992). Emotional coping and tonic blood pressure as determinants of cardiovascular response to mental stress. Journal of Hypertension, 10, (pp. 1079-1087).

Vogele, C., \& Steptoe, A. (1993). Anger inhibition and family history as modulators of cardiovascular responsivity to mental stress in adolescent boys. Journal of Psychosomatic Response. 37, (pp. 503-514).

Weitzman, E. A. \& Weitzman, P. F. (2006). The role of problem-solving and decision-making in conflict resolution. In M. Deutsch \& P. Coleman (Eds.) Theory and practice of conflict resolution. San Francisco: Jossey-Bass.

Weitzman, P.F. \& Weitzman, E. A. (2000). Interpersonal negotiation strategies in a sample of older women. Journal of Clinical Geropsychology_Vol. 6, No. 1.

Williams, F. \& Monge, P. (2001). Reasoning with statistics: How to read quantitative research. (5 ${ }^{\text {th }} \mathrm{ed}$ ). Belmont, CA: Thompson Higher Education.

Wood, E. (2004, July). Long-Term Care Mediation: Making it work. Paper presented at the University of Texas School of Nursing of Harris County for Lawyers and Mediators. Houston, TX.

Barbara Sunderland Manousso, PhD, MPH., is CEO of Manousso Mediation and Arbitration, LLC and Solution2Conflict. She has been in business since 1993. In 2017, the Association for Conflict Resolution Houston Chapter gave Dr Manousso a Lifetime Achievement Award for her work in the field of alternative dispute resolution.

She has trained mediators and worked as a mediator, arbitrator, ombudsman, facilitator, negotiator, conflict resolution coach and lecturer. She is also an author. For many years, she has been adjunct professor of Global Conflict Management at the University of St Thomas in Houston, TX, training foreign-service officers.

Dr Manousso mediates civil and family cases and specialises as an elder and adult care mediator. She has served on the international ACR Standards Committee for Elder Care Mediation Training. She has also lectured on civil, divorce, and elder mediation. Since 2008, she has served as a State Commissioner appointed by Texas governors to serve on the Texas' Nursing Facility Administrators

Advisory Committee.

She is a member of the University of Texas Consortium on Aging, is past-president of the Houston Gerontological Society, Brown University Alumni, and the University of Texas School of Public Health Alumni Association. 